\title{
A cidade colonizada pela mídia: poluição da comunicação no cenário urbano
}

Carlos Henrique Aiello Mestrando em Comunicação. UNIP-SP 


\section{Resumo}

As inúmeras transformações do cenário urbano - dentre elas o uso exagerado da mídia exterior nos últimos anos - decorrentes das disputas mercadológicas apoiadas nas estratégias publicitárias, recaem numa nova configuração dinâmica e social das cidades, reforçada por uma colonização cultural cada vez mais presente nos dias de hoje.

Palavras-chave

comunicação visual, poluição visual, mídia exterior, indústria cultural

\section{Abstract}

The innumerable transformations of the urban scenery - as the exaggerated use of external media during the last years - derived from the mercantile disputes supported by publicity strategies, result in a new dynamic and social configuration of the cities, reinforced by a cultural colonization which is becoming more and more present nowadays.

Key words

visual communication, visual pollution, external media, cultural industry 


\section{Introdução}

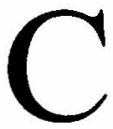

ada vez mais a sociedade busca esclarecer a dinâmica econômica e social numa nova ordem mundial na qual a informação passou a ser considerada como denominação de uma era, baseada numa economia global que é caracterizada pelo fluxo e troca quase instantâneos de informação, capital e comunicação cultural.

Os efeitos e implicações da transformação tecnológica na cultura da mídia, na vida urbana e na política econômica, têm provocado em grande escala o uso de estratégias de sobrevivência mercadológica em nossa sociedade pós-moderna, na qual o predomínio da imagem vem sendo explorado sob as formas mais diversas nos espaços urbanos. A partir da metade da década de 1940, após o final da Segunda Guerra Mundial, o conceito das organizações e os seus modos de produção passaram, pois, a experimentar gradativamente as mudanças e transformações ocorridas no ambiente externo.

A instabilidade e a imprevisibilidade, fruto do dinamismo e da complexidade do novo mundo, ficavam cada vez mais comuns no dia-a-dia do empresariado, onde os mercados refletiam sua expansão ao compasso de economias muitas vezes devastadoras e despreocupadas com suas conseqüências. As organizações trataram, então, de se preparar para enfrentar os novos desafios na tentativa de aumentar a sua competitividade frente às demais empresas do país ou do exterior, utilizando os seus próprios recursos de maneira mais eficiente e eficaz, sem deixar de lado, porém, a ambição de obter novas regalias. 
O fenômeno da Globalização, em que a competitividade extrapola os limites geográficos, exigiu e continua exigindo cada vez mais investimentos em diversas áreas como no Marketing, por exemplo, que engendra alternativas organizacionais num novo cenário mercadologicamente constituído. Para enfrentar a competição e a concorrência, aumentando a utilização ao máximo dos seus pontos fortes, as organizações passaram a investir e desenvolver alianças com outras empresas, esquemas cooperativos com fornecedores e, fusões entre entidades diferentes, constituindo as chamadas multinacionais e transnacionais, disseminando, assim, suas próprias culturas e ideologias.

\section{O papel da mídia exterior}

Dentre as estratégias do Marketing, a identificação do público-alvo e todo o processo de comunicação decorrente de um planejamento voltado a resultados, fez com que não fossem medidos esforços na maneira de comunicar, bem como em sua intensidade. Diante disso, as agências e os anunciantes desencadearam um maior fluxo de comunicação e esforço publicitário com a intenção de envolver um público cada vez maior. e, sobretudo, utilizaram plenamente as oportunidades de comunicar, influenciar e persuadir vendendo seus produtos e serviços e, mais do que nunca, descobrindo a importância e os resultados da interação e fidelização dos consumidores, apoiados em complexos processos comunicacionais.

Ao mesmo tempo em que os meios de comunicação se desenvolvem e se popularizam, as técnicas de elaboração e transmissão de mensagens são aprimoradas - e os chamados meios de comunicação alternativos representam uma significativa aproximação do público-alvo. Nesse contexto, encontra-se a paisagem urbana, meio de comunicação de massa que vem se transformando, com o passar dos anos, num um veículo eficaz da chamada mídia exterior que oferece aos consumidores mensagens instantâneas durante dias e dias através de diferentes formatos e tamanhos.

A mídia exterior possui a particularidade de que a informação é consumida a partir de diversos ângulos e, em razão de os seus 
componentes textuais terem como suporte o espaço urbano, institui, nas cidades, uma paisagem peculiar com capacidade de desempenhar, como assinala Mendes (2006), distintas funções. Desse ponto de vista, a maneira de comunicar que assume a mídia exterior, sempre criativa no uso de recursos retóricos, aperfeiçoa seu poder argumentativo prendendo, com surpreendente eficácia, a atenção dos consumidores. $\mathrm{O}$ espaço urbano das cidades passou, então, a ser a arena visível de uma colonização cultural em que agências e anunciantes, a partir dos investimentos na mídia exterior, reforçam os ideais de uma já constituída indústria cultural, que impõe sua ideologia a ponto de alterar a vida em sociedade.

\section{Mídia exterior e algumas de suas conseqüências}

A mídia exterior, enquanto alternativa poderosa no processo de colonização, com suas múltiplas formas e formatos, invade de maneira desenfreada o contexto urbanístico e nele deposita mensagens que, embora possuam um encanto singular, têm como conseqüência mais imediata a poluição visual e e a alteração dos significados de construtos arquitetônicos cujas mensagens obedecem as normas de outros códigos, isto é, o desmantelamento de um texto urbanístico cujos conteúdos mais legítmos, em termos das tradições arraigadas na cultura, são relegados a um plano secundário.

$\mathrm{O}$ acelerado crescimento nos investimentos publicitários $\mathrm{e}$ criação das mais variadas fórmulas midiáticas existentes estão, pois, a serviço e interesse do capital sempre comprometido com o objetivo de abrir novos horizontes para a sobrevivência mercadológica, pelo fato de influenciar culturas ao comunicar não só quais as reais vantagens competitivas de produtos e serviços, como também a própria existência desses produtos e serviços e suas conseqüências na sociedade - numa imensidão de ofertas empresariais resultante dos fenômenos da globalização econômica. Pode-se dizer, portanto, que essa exploração comercial vem modificando o cenário urbano e as mudanças do ambiente expressivo das cidades deixam perceber, 
de maneira explícita ou camuflada, o efeito de um trabalho colonizador, de um trabalho capaz de construir um imenso império midiático que, sem respeito algum, invade logradouros públicos ou privadose numa tetativa voraz e muitas vezes caótica de, através da exibitécnica, ampliar ao máximo seus domínios mercadológicos. É compreensível, nesse quadro, que as alternativas da mídia se multipliquem na medida em que novos espaços são conquistados e que os textos nascidos em função de uma constante infiltração imponham uma cultura própria, amiúde incompatível com a cultura do lugar e das pessoas que ali vivem em sociedade.

Enfim, a desordem de inúmeros elementos na paisagem urbanística - Banners, Luminosos, Placas, Painéis, Faixas, Cartazes, Murais, ect. - reflete bem as estratégias de colonização ancoradas na imagem. Sua poluição causa os mais diversos problemas, inclusive uma doença de nosso tempo: estresse perceptural.

Essa contextualização na mais variada forma de exploração e geração de produtos comunicacionais - a partir de uma análise imanente das imagens que decorrem dos mais variados veículos de comunicação como o outdoor, entre outros, vem contribuindo não só para uma poluição visual, mas também com uma nova doença moderna, até então, conhecida como estresse perceptual. Além do mais, como consqüências desse fenômeno, as fronteiras entre o espaço público e o privado se confundem e geram problemais sociais das mais diversas índoles.

\section{Considerações finais}

É necessário verificar até que ponto a ausência de comunicação gera uma não sobrevivência mercadológica, principalmente se pensarmos que produtos e serviços encontram-se equiparados e necessitam efetivar-se, utilizando as imagens estrategicamente, na mente de consumidores, já que os índices de compras port impulso são, os que, no fundo, sustentam um elevado acúmulo dos anúncios publicitários.

Considerando os espaços urbanos criados pelos homens no transcorrer de séculos e a organização da vida em comum, é de se 
admitir que a dinâmica da existência cotiniana não esteja submetida exclusivamente às normas do comércio. Para Lefebvre (1970), a sociedade urbana resulta da urbanização, fruto, em princípio, dos processos desencadeados pela era industrial e pós-industrial. O capital comercial e o mercado alteram assim o sentido da cidade que passa de uma realidade social para uma realidade urbana. As cidades começam a abrir-se para o mundo, em fluxos globalizados, formando as cibercidades. No início, a urbanização parece estar sobordinada à lógica da reprodução do capital. Mas, enquanto cenário e suporte, a cidade é também uma aglomeração de pessoas que vivenciam constantemente prazeres, desejos, necessidades e afetos. Para o pensador francês, o urbano é um problema novo gestado no século $\mathrm{XX}$ e apresenta matizes que não existiam no momento histórico em que se engendra marxismo.

Lefebvre aponta para as cidades contemporâneas da Era da Informação e sugere que as cidades - dominadas pelas cooperações multinacionais - são formas espaço-temporais construídas pelo transporte e a comunicação. A nova forma do urbano se caracteriza, pois, por estar globalmente posicionada e localmente esfacelada, explorada e, por conseguinte, colonizada pelos invisívies detentores do poder midiático. Vale dizer, portanto, que esses elementos, ordenados simbolicamente nos textos midiáticos, provocam nos receptores desses textos invasores do espaço urbano conseqüências que atingem pertubadoramente as emoções e as percepções do entorno cirunstancial. Diante desse panorama, é de se compreender que surjam reações.

Assim, a cidade de São Paulo, com o projeto de Lei 379/06, que determina a proibição de qualquer tipo de publicidade externa desde $1^{\circ}$ de janeiro de 2007 , ilustra bem uma das reações: outdoors, placas, painéis, pinturas em muros, anúncios em táxis, ônibus, bicicletas, trailers e, até mesmo em aeronaves, deverão ser removidos na ação que ficou conhecida como "cidade Limpa".

Levando em conta que, na cidade de São Paulo, o setor de mídia exterior movimenta $\mathrm{R} \$ 240$ milhões por ano, o que representa um terço do mercado nacional, que fatura anualmente $R \$ 650$ milhões e que 150 empresas operam nesse campo, a reação é significativa, 
principalmente se pensarmos na liberação da paisagem urbana e do renascimento de enunciados que foram sufocados pela intervenção. É necessário considerar, entretanto, que utilizados de maneira adequada, os construtos midiáticos, queiramos ou não, conferem à paisagem urbana conotações muito particulares e, desse ponto de vista, a cultura mediática, embora pareça paradoxal, mostra também a sua poesia.

\section{Bibliografia}

BAUMAN, Z. 2004. As conseqüências humanas. Rio de Janeiro: Jorge Zahar.

CANCLINI, Nestor García. 1999. Consumidores e cidadãos; conflitos multiculturais da globalização. Rio de Janeiro: Editora UFRJ.

CASTELLS, M. 1999. A sociedade em rede - A era da informática: economia, sociedade e cultura. Rio de Janeiro: Ed. Paz e Terra, 1999.

CONTRERA, Malena Segura. 2002. Mídia e pânico: saturação da informação, violência e crise cultural na mídia. São Paulo: Annablume, 2002.

FLUSSER, Vilém. 2002. Filosofia da Caixa preta: ensaios para uma futura filosofia da fotografia. Rio de Janeiro: Relume Dumará.

GIDDENS, Anthony. 2002. Modernidade e Identidade. Rio de Janeiro: Jorge Zahar.

GRUZINSK, Serge. 2006. A Guerra das imagens - De Cristóvão Colombo a Blade Runner (1492-2001). São Paulo: Cia das Letras.

HOMEM DE MELO, Francisco Inácio. 1985. Caos e ordem no ambiente urgano: exploração visula do signo arquitetônico e do significado informacional. Dissertação de mestrado. São Paulo: FAU-USP.

HALL, Stuart. 2005. A identidade cultural na pós-modernidade. Rio de Janeiro: DP\&A. 
LEFEBVRE, Henri. 1970. La Révoloution Urbaine. Paris: Gallimard.

MENDES, Camila Faccioni. 2006. Paisagem Urbana: uma mídia redescoberta. São Paulo: Editora SENAC.

MORIN, E. 1990. Cultura de Massas no sécuclo XX, vol. 1. São Paulo: Forense-Universitária.

TODOROV, Tzvetan. 1999. O homem desenraizado. São Paulo: Record. 